\title{
Clinical Profiles of Neonates Born to COVID-19 Positive Mothers in a Tertiary Care Centre: A Descriptive Cross-sectional Study
}

\author{
Shiva Prasad Sharma Chalise, ${ }^{1}$ Santosh Kumar Mishra, ${ }^{1}$ Bimal Sharma Chalise, ${ }^{2}$ Punam Rai, ${ }^{1}$ Subash Paudel, \\ Prerana Kansakar, ${ }^{1}$ Anil Raj Öha' \\ 'Department of Pediatrics, Patan Academy of Health Sciences, Lalitpur, Nepal, ${ }^{2}$ Sukraraj Tropical and Infectious \\ Disease Hospital, Teku, Kathmandu, Nepal.
}

\section{ABSTRACT}

Introduction: Nepal is one of the countries which has been hit hard by the COVID-19 pandemic and has resulted in high morbidity and mortality across all age groups including neonates. There has been a paucity of studies regarding maternal to neonatal COVID-19 transmission and the published studies also have a poor sample size to reach any definite conclusion. Hence this study was carried out to see the clinical profiles of neonates born to COVID-19 mothers.

Methods: It was a descriptive cross-sectional study. The study was conducted at a tertiary care centre over the period of one year from April 2020 to March 2021 after taking ethical clearance from the Institutional Review Committee with reference number drs2105211526. Convenient sampling was done. All neonates born to COVID-19 positive mothers who were diagnosed by a real-time polymerase chain reaction of the nasopharyngeal swab during the time of delivery were included in the study. Data analysis was done using Statistical Package for Social Sciences 20 using appropriate tools.

Results: A total of 105 babies born to COVID-19 positive mothers who were tested for COVID-19 infection were included in the study. Ten (9.5\%) (3.89-15.10 at 95\% Confidence Interval) of neonates born to COVID-19 positive mothers were positive for the COVID-19 virus. All the neonates born to COVID-19 positive mothers were discharged home except one case who had other comorbidities. Fever was present in four (40\%) of COVID-19 positive neonates.

Conclusions: There is a possibility of vertical transmission of coronavirus in neonates although the outcome is favourable.

Keywords: COVID-19; mothers; neonate.

\section{INTRODUCTION}

Nepal is one of the countries which has been hit hard by COVID-19 pandemic and has resulted in high morbidity and mortality across all age group including neonates. It has also caused significant reduction in institutional delivery with a negative impact on quality care thus leading to increase in institutional stillbirth and neonatal mortality rate. ${ }^{1}$

Studies have shown that up to ten percent of neonates born to COVID-19 positive mothers have positive viral tests. ${ }^{2}$ However a study done in Southeast Asia showed no maternal to neonatal COVID-19 transmission. ${ }^{3}$ There has been paucity of studies regarding maternal to neonatal COVID-19 transmission and the published studies also have poor sample size to reach any definite conclusion. ${ }^{2,3}$

Hence this study was carried out to see the clinical profiles of neonates born to COVID-19 positive mothers in a tertiary care hospital in Nepal.

\section{METHODS}

It was a descriptive cross-sectional study. The study was conducted in Patan Hospital, Lalitpur over the period

Correspondence: Dr. Shiva Prasad Sharma Chalise, Patan Academy of Health Sciences, Lalitpur, Nepal. Email: shivapschalise@pahs.edu.np, Phone: +977-9851129339. 
of one year from April 2020 to March 2021. The study was conducted after taking ethical clearance from the Institutional Review Committee with reference number drs2105211526. All neonates born to COVID-19 positive mothers who were diagnosed by real time polymerase chain reaction (RT PCR) of nasopharyngeal swab during the time of delivery were included in the study. Neonates born to antigen positive but RT PCR negative mothers, neonates born to COVID-19 positive mothers but not tested for COVID-19 and neonates whose file were missing were excluded from the study. Convenient sampling was done and the sample size was calculated using the formula,

$$
\begin{aligned}
\mathrm{n} & =\mathrm{Z}^{2} \times \mathrm{p} \times \mathrm{q} / \mathrm{e}^{2} \\
& =(1.96)^{2} \times 0.1 \times(1-0.1) /(0.06)^{2} \\
& =96
\end{aligned}
$$

Where,

$\mathrm{n}=$ minimum required sample size

$\mathrm{Z}=1.96$ at $95 \%$ Confidence Interval $(\mathrm{Cl})$

$p=$ prevalence from previous study $10 \%^{2}$

$q=1-p$

$\mathrm{e}=$ margin of error, $6 \%$

Though the convenient sampling was 96, we included all cases admitted in the time frame and collected data from 105 cases.

RT-PCR of all neonates born to COVID-19 positive mothers was sent at approximately 24 hours after delivery according to the hospital protocol. Maternal data of COVID-19 positive mother like age, pre-existing comorbidities like diabetes, hypertension, per vaginal leaking, gravida, parity, meconium-stained liquor, mode of delivery, antenatal care visits were recorded. Baby's data like gestational age, birth weight, Apgar score, COVID-19 status, transient tachypnoea of new born, respiratory distress syndrome, pneumonia, sepsis, need of mechanical ventilation, need of inotropes and duration of hospital stay were reviewed. Data were analysed using Statistical Package for Social Sciences (SPSS) version 20. Mean, median and standard deviation were used for continuous and normally distributed variables.

\section{RESULTS}

There were 107 babies born to COVID-19 positive mothers. Two cases were excluded as RT PCR was not sent. Final analysis was done among 105 cases. Ten (9.5\%) (3.89-15.10 at 95\% Confidence Interval) neonates were positive for COVID-19 PCR. Among all babies born to COVID-19 positive mothers, 38 (36.2 \%) had antenatal follow up outside the hospital. Mean and median maternal age was 28.4 and 28 with standard deviation of 4.4 years and range of $17-39$ years. Fifty two percent were male and forty eight percent were female. Mean and median weight of the baby was 2928 and 2990 grams with standard deviation of 574 grams and range of 840-3970 grams. Among them ninety-two $(87.6 \%)$ were term babies (Table 1 and Table 2 ).

\begin{tabular}{|lc|}
\hline $\begin{array}{l}\text { Table 1. Maternal details of } \\
\text { COVID-19 positive mothers. }\end{array}$ & neonates born to \\
\hline Maternal details & $\mathrm{n}(\%)$ \\
Primigravida & $49(46.7)$ \\
Caesarean delivery & $63(60)$ \\
Gestational diabetes & $4(3.8)$ \\
Gestational hypertension & $1(0.95)$ \\
PV leaking $>18$ hours & $2(1.9)$ \\
Meconium-stained liquor & $10(9.5)$ \\
\hline
\end{tabular}

Table 2. Baby details of neonates born to COVID-19 positive mothers.

\begin{tabular}{|ll|}
\hline Baby details & $\mathrm{n}(\%)$ \\
Gestational age $<37$ weeks & $13(12.4)$ \\
\hline Birth weight $<2500$ grams & $15(14.3)$ \\
Apgar score at 1 minutes $<7$ & $10(9.5)$ \\
\hline Need of resuscitation & $4(3.8)$ \\
COVID-19 Positive & $10(9.5)$ \\
\hline
\end{tabular}

Among them forty-two were delivered vaginally and sixty-three were delivered by caesarean section. Mode of delivery and maturity of the babies born to COVID-19 positive mothers (Figure 1).

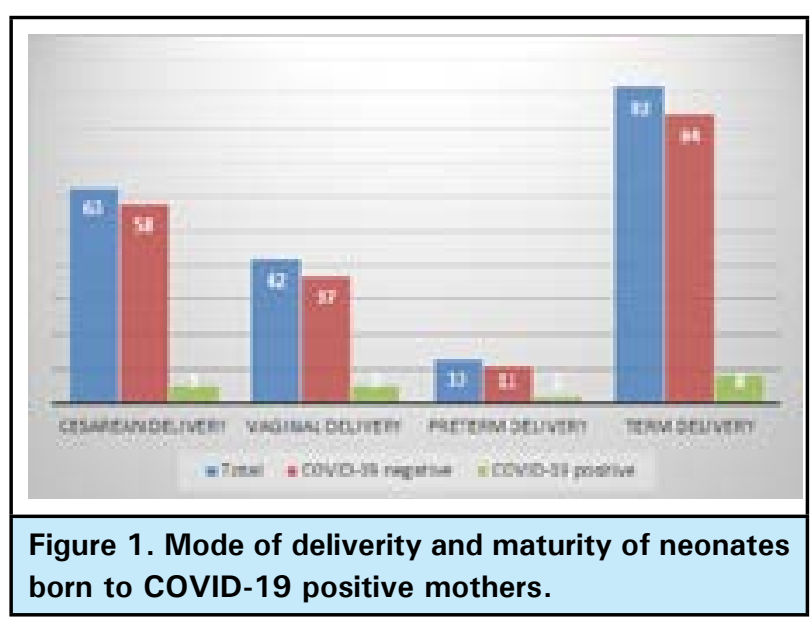

Five among them had symptoms. Clinical profiles of neonates born to COVID-19 positive mothers has been given (Table 3). Fever which was present in four cases. Three patient required respiratory support, two for respiratory distress syndrome and one for meconium aspiration syndrome. One baby expired among all cases. The baby was PCR positive but had other severe comorbidities. The patient was born at 30 weeks of gestation and required active resuscitation at birth. The baby also had tracheoesophageal fistula and surgery was planned but not done due to hemodynamic instability. The baby required ventilator and inotropic support for 13 days. The baby expired at 13 days of life. 
Among all cases eighty-one babies were discharged after PCR report and discussion with parents within 72 hours. Ninety-three patients were discharged within seven days and twelve patients had hospital stay of more than seven days. Among them eight were preterm, one was culture positive (coagulase negative staphylococcus) sepsis, one was birth asphyxia, another one treated as meningitis, one congenital heart disease. Four of them stayed for more than two weeks among them three were preterm and one was meningitis.

\begin{tabular}{|c|c|c|c|}
\hline Clinical profile & $\begin{array}{l}\text { COVID-19 } \\
\text { Positive } \\
\text { neonates } \\
(n=10)(\%)\end{array}$ & $\begin{array}{l}\text { COVID-19 } \\
\text { Negative } \\
\text { neonates } \\
(n=95) n \\
(\%)\end{array}$ & $\begin{array}{l}\text { All } \\
\text { Neonates } \\
\text { born to } \\
\text { CoVID-19 } \\
\text { positive } \\
\text { mothers } \\
(n=105) n \\
(\%)\end{array}$ \\
\hline $\begin{array}{l}\text { Mechanical } \\
\text { ventilation }\end{array}$ & $2(20)$ & $3(3.2)$ & $5(4.8)$ \\
\hline $\begin{array}{l}\text { Need of } \\
\text { inotropes }\end{array}$ & $1(10)$ & $1(1.0)$ & $2(1.9)$ \\
\hline Fever & $4(40)$ & $9(9.5)$ & $13(12.4)$ \\
\hline $\begin{array}{l}\text { Oxygen } \\
\text { required }\end{array}$ & $3(30)$ & $8(8.4)$ & $11(10.5)$ \\
\hline $\begin{array}{l}\text { Transient } \\
\text { tachypnea of } \\
\text { newborn }\end{array}$ & $0(0)$ & $5(5.3)$ & $5(4.8)$ \\
\hline $\begin{array}{l}\text { Respiratory } \\
\text { distress } \\
\text { syndrome }\end{array}$ & $2(20)$ & $3(3.2)$ & $5(4.8)$ \\
\hline $\begin{array}{l}\text { Meconium } \\
\text { aspiration } \\
\text { syndrome }\end{array}$ & $1(10)$ & $0(0)$ & $1(1)$ \\
\hline $\begin{array}{l}\text { Sepsis } \\
\text { (Coagulase } \\
\text { negative } \\
\text { staphylococcus) }\end{array}$ & $0(0)$ & $1(1.0)$ & $1(1)$ \\
\hline
\end{tabular}

\section{DISCUSSION}

Centre for Disease Control and Prevention (CDC) recommends COVID-19 testing of all new-borns born to COVID-19 positive mothers at approximately 24 hours and 48 hours of life irrespective of sign and symptoms. ${ }^{4}$ There are conflicting results from previous studies on the risk of vertical transmission of coronavirus in neonates. This study shows 9.5 percent of neonates born to COVID-19 positive mother to be positive for COVID-19 virus. This result is similar to a study from India in which out of 65 tested neonates, $10.7 \%$ were confirmed COVID-19 positive by RTPCR. ${ }^{2}$ The study further showed viral loads of mothers with COVID-19 positive and negative neonates were comparable. In another study from India, among 221 new-borns 14.47 percent were positive. ${ }^{5}$ In another study four out of 120 new-borns were positive for the virus. ${ }^{6}$ In a study among two hundred four deliveries, there were no positive newborns. ${ }^{7}$ In another two studies including 82 and 38 neonates born to COVID-19 positive mother also there were no positive cases. ${ }^{8,9}$ Systemic reviews have shown about three percent neonates acquired infection through possible vertical transmission. ${ }^{10,11}$ Though there are chances that neonates might have acquired COVID-19 after birth or positive reports may be due to contamination of samples, studies and case reports have shown COVID-19 virus to be present in amniotic fluid, cord blood, placenta and breast milk. ${ }^{12}$ 15 The COVID-19 virus binds to Angiotensin-converting enzymes 2 receptor which is present in ovary, uterus, vagina, placenta, syncytiotrophoblast, cytotrophoblast, endothelium and vascular smooth muscles from primary and secondary villi. These findings point towards possible vertical transmission.

Most studies show higher caesarean rates among COVID-19 positive pregnancies. Forty-four to eighty percent deliveries were caesarean in different studies. ${ }^{6,8,16,17}$ This study shows a caesarean rate of sixty percent. Higher caesarean rate may be due to maternal altered food habits, physical activities and the stress related to the pandemic affecting the intrauterine growth in the weight of the baby. ${ }^{18}$ This study shows that risk of getting COVID-19 infection in vaginal delivery is 13.5 percent while in caesarean section it is 8.6 percent. A study from India shows 17.6 and 13.2 percent respectively. ${ }^{5}$ The study shows prematurity and low birth weight to be 12 and 14 percent respectively. A study by Sindy showed 38 percent case to be prematurity and 33 percent cases to be low birth weight. ${ }^{19}$ Another study shows that the most common adverse pregnancy outcome was premature. ${ }^{7}$ Need to terminate the pregnancy for maternal condition like pneumonia, acute respiratory distress syndrome, preeclampsia maybe the reason to have more premature deliveries in COVID-19 mothers. Though this study does not show significant higher prematurity and low birth weight babies.

A metanalysis showed among COVID-19 positive neonates fever was the most common neonatal symptom (40\%), followed by shortness of breath (28 $\%)$ and vomiting (24\%), while $20 \%$ of neonates were totally asymptomatic. ${ }^{17}$ Our study also has similar result with fever in 40 percent cases among 10 COVID positive cases. Studies have shown that COVID-19 infected neonates have generally good outcome. Six of the 7 neonates were asymptomatic and 1 neonate needed respiratory support (indication being prematurity) which resolved after 48 hours. ${ }^{2}$ In another study where four $(3.3 \%)$ of 120 new-borns were positive, all were 
asymptomatic. ${ }^{6}$ A report from India showed all six neonates to be asymptomatic. ${ }^{20}$ This study also has favourable outcome except in one which also had other severe comorbidity. Possible transfer of antibodies from mother to baby might have given protection against COVID-19 in newborns. ${ }^{21}$

The study shows the possibility of maternal to neonatal transmission. Although there is possibility that newborns can acquire COVID-19 infection following birth, there is still a high probability that it can be transmitted vertically. However, the outcome of these neonates who are infected is good. There are few limitations of this study. One of them is a small sample size. RTPCR negative new-borns not routinely tested after 48 hours. Repeating test even after 48 hours could have even added the positive cases. Identifying the virus in amniotic fluid, cord blood and in the baby before twelve hours of life could have helped to establish the vertical transmission.

\section{CONCLUSIONS}

COVID-19 in neonates is not an uncommon entity. There is a possibility of vertical transmission of coronavirus in neonates although the outcome is favourable. Further studies with larger sample size with testing of amniotic fluid, cord blood and placenta are required to validate the findings of our study.

Conflict of Interest: None.

\section{REFERENCES}

1. Ashish KC, Gurung R, Kinney MV, Sunny AK, Moinuddin $\mathrm{M}$, Basnet $\mathrm{O}$, et al. Effect of the COVID-19 pandemic response on intrapartum care, stillbirth, and neonatal mortality outcomes in Nepal: a prospective observational study. The Lancet Global Health. 2020 Oct 1;8(10):e1273-81. [PubMed | FullText $\mid$ DOI]

2. Anand P, Yadav A, Debata P, Bachani S, Gupta N, Gera R. Clinical profile, viral load, management and outcome of neonates born to COVID-19 positive mothers: a tertiary care centre experience from India. European Journal of Pediatrics. 2021 Feb;180(2):547-59. [PubMed | FullText | DOI]

3. Mattar CN, Kalimuddin S, Sadarangani SP, Tagore S, Thain S, Thoon KC, et al. Pregnancy outcomes in COVID-19: a prospective cohort study in singapore. Annals of the Academy of Medicine, Singapore. 2020 Nov 1;49(11):857-69. [PubMed | Full Text $\mid \underline{\text { DOI] }}$

4. Evaluation and management considerations for neonates At risk for COVID-19. United States: CDC; [updated 2020 Aug 3; cited 2021 July 28]. Available at: https://www.cdc.gov/ coronavirus/2019-ncov/hcp/caring-for-newborns.html. [Full Text]

5. Ajith S, Reshmi VP, Nambiar S, Naser A, Athulya B. Prevalence and risk factors of neonatal COVID-19 infection: A Single-Centre Observational Study. The Journal of Obstetrics and Gynecology of India. 2021 Feb 4:1-4. [PubMed | Full Text | DOI]

6. Oncel MY, Akın IM, Kanburoglu MK, Tayman C, Coskun S, Narter F, Er I, Oncan TG, Memisoglu A, Cetinkaya M, Oguz D. A multicenter study on epidemiological and clinical characteristics of 125 newborns born to women infected with COVID-19 by Turkish Neonatal Society. European journal of pediatrics. 2021 Mar;180(3):733-42. [ㄷllText | DOI]

7. Alzamora MC, Paredes T, Caceres D, Webb CM, Valdez LM, La Rosa M. Severe COVID-19during pregnancy and possible vertical transmission. American journal of perinatology. 2020 Jun;37(8):861. [․ㅏbMed | FullText | DOI]

8. Salvatore CM, Han JY, Acker KP, Tiwari P, Jin J, Brandler M, Cangemi C, Gordon L, Parow A, DiPace J, DeLaMora P. Neonatal management and outcomes during the COVID-19 pandemic: an observation cohort study. The Lancet Child \& Adolescent Health. 2020 Oct 1;4(10):721-7. [PubMed | FullText | DOI]

9. Schwartz DA. An analysis of 38 pregnant women with COVID-19, their newborn infants, and maternal-fetal transmission of SARS-CoV-2: maternal coronavirus infections and pregnancy outcomes. Arch Pathol Lab Med. 2020;144(7):799-805. [uㅏㄹed | FullText | DOI]

10. Kotlyar A, Grechukhina O, Chen A, Popkhadze S, Grimshaw A, Tal O, et al. Vertical transmission of COVID-19: a systematic review and meta-analysis. American journal of obstetrics and gynecology. 2020 Jul 31. [uㅏㄹed | FullText I DOI]

11. Sheth S, Shah N, Bhandari V. Outcomes in COVID-19 positive neonates and possibility of viral vertical transmission: a narrative review. American Journal of Perinatology. 2020 Oct;37(12):1208. [ [PubMed | FullText | DOI]

12. Zamaniyan M, Ebadi A, Mir SA, Rahmani Z, Haghshenas M, Azizi S. Preterm delivery in pregnant woman with critical COVID-19 pneumonia and vertical transmission. Prenatal diagnosis. 2020 Apr 17. [ubMed | FullText | DOI]

13. Vivanti AJ, Vauloup-Fellous C, Prevot S, Zupan V, Suffee C, Do Cao J, Benachi A, De Luca D. Transplacental transmission of SARS-CoV-2 infection. Nature communications. $2020 \mathrm{Jul}$ 14;11(1):1-7. [PubMed | FullText | DOI]

14. Buonsenso D, Costa S, Sanguinetti M, Cattani P, Posteraro B, Marchetti S, Carducci B, Lanzone A, Tamburrini E, Vento G, Valentini P. Neonatal late onset infection with severe acute respiratory syndrome coronavirus 2. American journal of perinatology. 2020 Jun;37(8):869. [PubMed | FullText | DOI]

15. Wu Y, Liu C, Dong L, Zhang C, Chen Y, Liu J, Zhang C, Duan C, Zhang H, Mol BW, Dennis CL. Coronavirus disease 2019 among pregnant Chinese women: case series data on the safety of vaginal birth and breastfeeding. BJOG: An International Journal of Obstetrics \& Gynaecology. 2020 Aug;127(9):1109-15. [uㅣㄹed | FullText | DOI]

16. Alzamora MC, Paredes T, Caceres D, Webb CM, Valdez LM, La Rosa M. Severe COVID-19 during pregnancy and possible vertical transmission. American journal of perinatology. 


\section{Jun;37(8):861. [․ㅏbMed | FullText | DOI]}

17. Bellos I, Pandita A, Panza R. Maternal and perinatal outcomes in pregnant women infected by SARS-CoV-2: A meta-analysis. European Journal of Obstetrics \&Gynaecology and Reproductive Biology. 2020 Nov 13. [PubMed | FullText | DOI]

18. Zhang J, Zhang Y, Ma Y, Ke Y, Huo S, He L, Luo W, Li J, Zhao A. The associated factors of cesarean section during COVID-19 pandemic: a cross-sectional study in nine cities of China. Environmental health and preventive medicine. 2020 Dec;25(1):1-7. [uㅏㅇㅣ | FullText | DOI]
19. Moreno SC, To J, Chun H, Ngai IM. Vertical Transmission of COVID-19 to the Neonate. Infectious diseases in obstetrics and gynecology. 2020 Nov 12;2020. [ $\underline{\text { PubMed }}$ | FullText | DOI]

20. Banerjee S, Guha A, Das A, Nandi M, Mondal R. A preliminary report of COVID-19 in children in India. Indian pediatrics. 2020 Oct;57(10):963-4. [PubMed | FullText | DOI]

21. Kohler PF, Farr RS. Elevation of cord over maternal IgG immunoglobulin: evidence for an active placental IgG transport. Nature. 1966 Jun 4;210(5040):1070-1. [ [PubMed | FullText | DOI]

This work is licensed under a Creative Commons Attribution 4.0 International License. The images or other third party material in this article are included in the article's Creative Commons license, unless indicated otherwise in the credit line; if the material is not included under the Creative Commons license, users will need to obtain permission from the license holder to reproduce the material. To view a copy of this license, visit http://creativecommons.org/licenses/by/4.0/ 